\title{
Parkinson's disease sleep scale, sleep logs, and actigraphy in the evaluation of sleep in parkinsonian patients
}

\author{
Santiago Perez-Lloret $\cdot$ Malco Rossi · \\ María Inés Nouzeilles · Claudia Trenkwalder · \\ Daniel P. Cardinali · Marcelo Merello
}

Received: 17 December 2008/Revised: 20 March 2009/Accepted: 15 April 2009/Published online: 29 April 2009

(c) Springer-Verlag 2009

\begin{abstract}
The aim of this study was to compare the results of the day-to-day self-evaluation of sleep quality by sleep logs with Parkinson's disease sleep scale (PDSS) in Parkinson's disease (PD) patients. Actigraphy was used as an independent analysis of nighttime activity interfering with sleep. A total of 71 idiopathic PD patients and 21 age- and sex-matched normal individuals lacking any type of sleep disturbance were recruited. Sleep was evaluated by PDSS, 7-d sleep log and actigraphy. Sleep $\operatorname{logs}$ and PDSS showed reduced sleep quality and daytime somnolence scores in moderate/severe PD patients as compared to healthy controls. Significant correlations were found between sleep quality in sleep logs and all domains of PDSS sleep quality, except for the presence of nocturia, which correlated with nocturnal activity. PD severity and depression were the only predictors of reduced sleep quality. The retrospective and day-to-day sleep self-evaluations were coincident. Reduced sleep quality was related to increased PD severity and depression scores.
\end{abstract}

S. Perez-Lloret · M. Rossi · M. I. Nouzeilles · M. Merello ( $\square)$ Movement Disorders Section, Raul Carrea Institute for Neurological Research, FLENI, Montañeses 2325 (C1428AQK), Cdad. Aut. Buenos Aires, Argentina

e-mail: mmerello@fleni.org.ar

S. Perez-Lloret

e-mail: splloret@fleni.org.ar

S. Perez-Lloret · M. Rossi - D. P. Cardinali

Department of Physiology, Faculty of Medicine,

University of Buenos Aires, Paraguay 2155,

Buenos Aires, Argentina

C. Trenkwalder

Paracelsus-Elena-Hospital, Kassel, Germany

C. Trenkwalder

University of Goettingen, Göttingen, Germany
Keywords Sleep logs $\cdot$ Parkinson's disease · Actigraphy · Sleep disorders $\cdot$ Sleep evaluation

\section{Introduction}

Up to $90 \%$ of Parkinson's disease (PD) patients complain of sleep problems [11, 14, 24]. The most commonly observed sleep disorders in PD patients are linked to nocturnal motor disorder, including off-state dystonia, cramps, tremor, or severe akinesia and rigidity producing painful postures and problems when turning in bed as well as neuropsychiatric symptoms, i.e., vivid dreams, nocturnal hallucinations, and REM sleep behavior disorder [3, 6, 12]. Periodic limb movements disorder and nocturia are also commonly observed in PD [3, 7, 12].

The 15-item Parkinson's disease sleep scale (PDSS) has been developed for retrospective sleep self-evaluation in PD $[3,17]$. The scale is reliable, is able to differentiate healthy controls from PD patients, and correlates well with disease severity. The daytime somnolence item (\#15) and restlessness item (\#4) have received support from the Epworth score [3] and International Restless Legs Syndrome Study Group diagnostic criteria [25], respectively. One of its limitations is that it is based on 15-d retrospective sleep quality self-evaluation.

On the other hand, sleep logs allow a day-to-day evaluation of bedtime, rising time, sleep latency, number and duration of awakenings, naps, and some indexes of sleep quality [23]. Though sleep logs are widely used for sleep evaluation in healthy subjects and insomniacs [4, 21, 23], they have not been systematically assessed in PD.

In the present study, the day-to-day sleep quality selfevaluation by sleep log was compared to PDSS results. 
Actigraphy was used as an independent analysis of nighttime activity interfering with sleep.

\section{Methods}

Study sample

PD patients were recruited from a tertiary out-patient clinic. To be included, subjects had to fulfill the United Kingdom Parkinson's Disease Society Brain Bank criteria [16] and have a mini-mental state examination (MMSE) score $>24$ points.

A group of healthy controls frequency-matched for sex and age, without sleep complaints, chronic diseases or secondary causes of insomnia, and not taking any type of hypnotic medication, were recruited from the general population. The protocol conforms to the principles enumerated in the Helsinki Declaration, was approved by the Institutional Review Board, and all subjects signed an informed consent after full explanation of the procedures.

\section{PD evaluation}

PD patients were subjected to cognitive, psychiatric, and motor evaluation including the MMSE [10], MontgomeryAsberg Depression Rating scale (MADRS) [20], Unified PD rating scale (UPDRS) [9], and Hoehn \& Yahr scale $(\mathrm{H} \& \mathrm{Y})$ [15]. Medication records were used to calculated levodopa equivalent daily dose (LDED) according to the usual formula [22].

\section{PDSS}

PD patients and healthy controls completed the selfadministered Spanish version of PDSS during their clinical interviews [17]. For evaluation of the results, PDSS items were grouped according to domain: sleep quality (items 13 ); nocturnal restlessness (items 4 and 5); nocturnal psychosis (items 6 and 7), nocturia (item 8); nocturnal motor symptoms (items 9-13) and daytime somnolence (items 14 and 15) [25].

\section{Sleep diary and actigraphy}

After the initial clinical interview, a standard sleep log was completed by patients and controls every day after waking up. Information about the time at which subjects fell asleep and woke up, as well as the number and duration of perceived awakenings were registered [1, 2]. It also included three $10 \mathrm{~cm}$ visual analog scales for quantification of sleep latency ("a lot"-"a little"), sleep quality ("bad"-"good") and morning freshness (i.e., how tired the subject felt on waking, "a lot"-“a little”). Total sleep log scores were calculated as the sum of all three items, ranging between 0 and 30.

Participants were instructed to wear an actigraphy device (MicroMini-Motionlogger, Ambulatory Monitoring Inc, NY, USA) in addition to completing the 7-d sleep log. The actigraphic device was attached to the non-dominant wrist [18]. Nocturnal activity, nocturnal motility time, and time in bed were calculated using Action W 2.5 software (Ambulatory Monitoring Inc, NY, USA).

Statistical analysis

Categorical data were compared using chi-square, and numerical variables by ANOVA. Factor analysis was used to check the reliability of the sleep logs. The Pearson correlation coefficient was employed to assess the associations between PDSS, sleep log, and actigraphy.

Sleep log scores and nocturnal activity were related to the characteristics of PD and its treatment by multiple linear regression.

Actigraphic data were log transformed to render them normally distributed. Data are expressed as mean \pm standard error of the mean unless otherwise stated. Alfa error was set at 0.05 .

\section{Results}

A total of 71 PD patients and 25 age- and sex-matched controls were recruited. Four controls were excluded because of incomplete data. Age was $64.4 \pm 2.0$ years in controls and $68.5 \pm 1.0$ years in PD patients $(p=0.1)$. No gender differences were noticed between controls and patients (29 and 49\% were males, respectively, $p=0.1$ ).

PD patients showed UPDRS II scores (daily living), III (motor score), and IV (levodopa complication scores) of $11.4 \pm 0.8,17.8 \pm 1.2,2.9 \pm 0.5$, respectively. The sum of these scores (UPDRS II-IV) was $32.0 \pm 1.9$. Median Hoehn \& Yahr score was 2 (interquartile range 1.5-3). Mean disease duration was $7.7 \pm 0.7$ years and mean MMSE and MADRS scores were $29.1 \pm 0.2$ and $7.0 \pm 0.8$, respectively. Out of the 71 PD patients, 14 were medication-naïve (20\%). In treated subjects, mean LDED was $596.9 \pm 54.9 \mathrm{mg} / \mathrm{d}$. Fifteen $(21 \%)$ patients received only levodopa, while 14 (20\%), 13 (18\%), 10 (14\%), and 5 (7\%) patients received also piribedil, cabergoline, pramipexol, or other dopaminergic agonists, respectively.

Sleep evaluation in PD patients

As summarized in Table 1, sleep quality was significantly worse in PD patients as compared to controls when 
Table 1 Comparison of sleep log and actigraphic data between PD patients and controls

\begin{tabular}{|c|c|c|c|c|}
\hline & Controls $(n=21)$ & H\&Y I-II $(n=46)$ & H\&Y III-V $(n=25)$ & $p$ \\
\hline \multicolumn{5}{|l|}{ PDSS } \\
\hline Sleep quality & $22.69 \pm 1.09$ & $19.8 \pm 0.85^{*}$ & $18.46 \pm 1.23 *$ & 0.05 \\
\hline Nocturnal restlessness & $16.43 \pm 0.42$ & $15.8 \pm 0.45$ & $14.83 \pm 0.72$ & 0.2 \\
\hline Nocturnal psychosis & $17.81 \pm 0.5$ & $16.27 \pm 0.48$ & $14.24 \pm 0.84^{*}$ & $0.002^{\mathrm{a}}$ \\
\hline Nocturia & $4.69 \pm 0.71$ & $3.74 \pm 0.49$ & $4.55 \pm 0.7$ & 0.5 \\
\hline Nocturnal motor symptoms & $44.65 \pm 0.66$ & $42.02 \pm 0.93$ & $38.37 \pm 1.72 *$ & $<0.01^{\mathrm{a}}$ \\
\hline Daytime somnolence & $16.51 \pm 0.37$ & $14.13 \pm 0.6^{*}$ & $11.99 \pm 0.93 *$ & $<0.001^{\mathrm{a}}$ \\
\hline PDSS total score & $122.78 \pm 1.77$ & $111.78 \pm 2.38^{*}$ & $102.43 \pm 3.71 *$ & $<0.001^{\mathrm{a}}$ \\
\hline \multicolumn{5}{|l|}{ Sleep log } \\
\hline Sleep latency & $1.93 \pm 0.39$ & $1.99 \pm 0.21$ & $2.22 \pm 0.28$ & 0.8 \\
\hline Sleep quality & $7.5 \pm 0.37$ & $6.87 \pm 0.25$ & $5.89 \pm 0.23^{*}$ & $0.003^{\mathrm{a}}$ \\
\hline Morning alertness & $7.29 \pm 0.43$ & $6.99 \pm 0.24$ & $6.15 \pm 0.38$ & 0.08 \\
\hline Total sleep log score & $22.41 \pm 0.91$ & $21.86 \pm 0.56$ & $19.82 \pm 0.56^{*}$ & 0.03 \\
\hline Awakenings number & $1.31 \pm 0.24$ & $1.57 \pm 0.14$ & $1.82 \pm 0.14$ & 0.2 \\
\hline Awakening time (min) & $19.75 \pm 4.66$ & $26.14 \pm 4.47$ & $38.92 \pm 6.73$ & 0.8 \\
\hline Nap time (min) & $20.29 \pm 7.06$ & $34.71 \pm 4.54$ & $47.3 \pm 6.69^{*}$ & 0.02 \\
\hline \multicolumn{5}{|l|}{ Actigraphy } \\
\hline Nocturnal activity (counts) & $732.53 \pm 76.73$ & $887.41 \pm 77.53$ & $1029.64 \pm 179.53$ & 0.5 \\
\hline Nocturnal motility time (min) & $30.69 \pm 4.77$ & $35.3 \pm 3.56$ & $38.47 \pm 6.9$ & 0.6 \\
\hline Time in bed (min) & $458.34 \pm 15.73$ & $421.67 \pm 8.33$ & $415.12 \pm 11.71$ & 0.04 \\
\hline
\end{tabular}

PDSS total score is the sum of all its domains. Sleep log total score is obtained as: sleep quality + morning alertness $+(10-$ sleep latency) $* p<0.05$ versus controls (ANOVA followed by Dunnett's post-hoc test)

${ }^{a}$ Brown-Forsythe adjustment for unequal variances was employed

evaluated either by PDSS or by sleep log. While advanced PD patients (H\&Y III-V) showed striking sleep disturbance, mild/moderate PD patients (H\&Y I-II) showed less sleep deterioration, reaching significance only in PDSS sleep quality, daytime somnolence, and PDSS total score.

Comparison of historical sleep data provided by PDSS with day-to-day assessment by sleep log and actigraphy

Significant correlations between PDSS and sleep log were found (Table 2). As can be seen, in general, sleep log quality scores correlated with all PDSS subdomains, except for Nocturia, which correlated only with increased awakening numbers, reduced morning alertness, and higher nocturnal activity.

The internal consistency of sleep logs sleep quality indicators were evaluated by factor analysis. Only one factor including sleep latency, sleep quality, and morning alertness, explaining $60 \%$ of total variance, could be found.

A multiple regression analysis showed that, on one hand, sleep log total score was independently related to H\&Y score $(r=-0.25, p=0.05)$ and MADRS score $(r=-0.24, p=0.05)$. On the other hand, nocturnal activity correlated with $\operatorname{LDED}(r=-0.40, p=0.02)$ and MMSE score $(r=-0.25, p=0.05)$.

\section{Discussion}

In the present study, day-to-day sleep assessment by sleep logs was compared to PDSS retrospective sleep evaluation. The foregoing results indicate that daily evaluations of sleep quality by sleep log correlated significantly with most PDSS subdomains, suggesting that both tools can evaluate sleep quality to a similar extent. Moreover, sleep quality evaluated by sleep logs was related to disease severity and depression in PD, which coincides with previous reports [3, 11, 25].

The main limitation of this study is that polysomnography (PSG) was not used as the reference method for sleep evaluation. Nonetheless, the significant divergence between PSG and subjective sleep evaluation observed in PD [13] as well as the result that subjective more than objective findings of impaired sleep quality impact negatively on quality of life [19] suggest that PSG may not be the best method against which subjective sleep evaluation tools should be compared.

Many questions on the sleep log and PDSS are similar, providing the basis for the results herein observed. Nonetheless, while the PDSS retrospectively assesses sleep quality in 15 days constituting a simple bedside screening of sleep disturbances in PD, the degree of detail provided 
Table 2 Relationships between PDSS, sleep log, and actigraphy in PD patients

\begin{tabular}{|c|c|c|c|c|c|c|c|}
\hline \multirow[b]{2}{*}{ PDSS domains } & \multicolumn{6}{|l|}{ Sleep $\log$} & \multirow{2}{*}{$\begin{array}{l}\text { Actigraphy } \\
\text { Nocturnal } \\
\text { motility time }\end{array}$} \\
\hline & $\begin{array}{l}\text { Sleep } \\
\text { latency }\end{array}$ & $\begin{array}{l}\text { Sleep } \\
\text { quality }\end{array}$ & $\begin{array}{l}\text { Morning } \\
\text { alertness }\end{array}$ & Total score & $\begin{array}{l}\text { Awakenings } \\
\text { number }\end{array}$ & $\begin{array}{l}\text { Awakenings } \\
\text { time }\end{array}$ & \\
\hline Sleep quality & $\begin{array}{r}r=-0.31 \\
\quad(p<0.01)\end{array}$ & $\begin{array}{l}r=0.50 \\
\quad(p<0.01)\end{array}$ & $\begin{array}{l}r=0.41 \\
\quad(p<0.01)\end{array}$ & $\begin{array}{l}r=0.59 \\
\quad(p<0.01)\end{array}$ & $\begin{array}{l}r=-0.14 \\
\quad(p=0.2)\end{array}$ & $\begin{array}{r}r=-0.33 \\
\quad(p<0.01)\end{array}$ & $\begin{array}{l}r=-0.10 \\
\quad(p=0.36)\end{array}$ \\
\hline $\begin{array}{l}\text { Nocturnal } \\
\text { restlessness }\end{array}$ & $\begin{array}{l}r=-0.14 \\
\quad(p=0.9)\end{array}$ & $\begin{array}{l}r=0.43 \\
\quad(p<0.01)\end{array}$ & $\begin{array}{l}r=0.32 \\
\quad(p<0.01)\end{array}$ & $\begin{array}{l}r=0.31 \\
\quad(p<0.01)\end{array}$ & $\begin{array}{l}r=0.02 \\
\quad(p<0.9)\end{array}$ & $\begin{array}{l}r=-0.29 \\
\quad(p<0.01)\end{array}$ & $\begin{array}{r}r=-0.08 \\
(p<0.7)\end{array}$ \\
\hline Nocturnal psychosis & $\begin{array}{r}r=-0.16 \\
(p<0.5)\end{array}$ & $\begin{array}{l}r=0.21 \\
\quad(p<0.05)\end{array}$ & $\begin{array}{l}r=0.24 \\
\quad(p<0.04)\end{array}$ & $\begin{array}{l}r=0.25 \\
\quad(p<0.01)\end{array}$ & $\begin{array}{l}r=0.06 \\
\quad(p<0.9)\end{array}$ & $\begin{array}{l}r=-0.27 \\
\quad(p<0.01)\end{array}$ & $\begin{array}{r}r=-0.20 \\
\quad(p<0.07)\end{array}$ \\
\hline Nocturia & $\begin{array}{r}r=-0.03 \\
\quad(p<0.6)\end{array}$ & $\begin{array}{l}r=0.03 \\
\quad(p<0.9)\end{array}$ & $\begin{array}{r}r=-0.31 \\
\quad(p<0.01)\end{array}$ & $\begin{array}{l}r=-0.1 \\
\quad(p<0.2)\end{array}$ & $\begin{array}{r}r=-0.28 \\
\quad(p<0.04)\end{array}$ & $\begin{array}{l}r=0.03 \\
\quad(p<0.9)\end{array}$ & $\begin{array}{r}r=-0.30 \\
\quad(p<0.01)\end{array}$ \\
\hline $\begin{array}{l}\text { Nocturnal motor } \\
\text { symptoms }\end{array}$ & $\begin{array}{r}r=-0.15 \\
\quad(p<0.4)\end{array}$ & $\begin{array}{l}r=0.48 \\
\quad(p<0.01)\end{array}$ & $\begin{array}{l}r=0.56 \\
\quad(p<0.001)\end{array}$ & $\begin{array}{l}r=0.50 \\
\quad(p<0.01)\end{array}$ & $\begin{array}{l}r=0.05 \\
\quad(p<0.8)\end{array}$ & $\begin{array}{l}r=-0.39 \\
\quad(p<0.01)\end{array}$ & $\begin{array}{r}r=-0.03 \\
(p<0.8)\end{array}$ \\
\hline Diurnal somnolence & $\begin{array}{r}r=-0.10 \\
(p<0.5)\end{array}$ & $\begin{array}{l}r=0.26 \\
\quad(p<0.03)\end{array}$ & $\begin{array}{l}r=0.28 \\
\quad(p<0.02)\end{array}$ & $\begin{array}{l}r=0.30 \\
\quad(p<0.01)\end{array}$ & $\begin{array}{r}r=-0.11 \\
(p<0.3)\end{array}$ & $\begin{array}{r}r=-0.12 \\
(p<0.2)\end{array}$ & $\begin{array}{r}r=-0.10 \\
(p<0.5)\end{array}$ \\
\hline
\end{tabular}

Data was analyzed by Pearson methods. Actigraphic variables were log transformed

by the sleep logs make them suitable for analysis of particular cases or for clinical interventional studies.

Actigraphy is a common companion to the sleep log [4, $21,23]$. Its use in PD sleep studies [5, 8] has been questioned mainly because it may not be accurate enough to discern sleep state from PD-related immobility or tremor [12], which was confirmed in our study.

In summary, retrospective sleep quality evaluation by the PDSS and day-to-day evaluation by sleep log coincided. While PDSS can be used as a simple bedside sleep disturbances screening tool, sleep logs are suitable for analysis of particular cases or for clinical interventional studies. On the other hand, while utility of actigraphy for nocturnal activity measurement is warranted, its role in sleep evaluation in PD appears to be very limited.

Acknowledgments This study was supported by grants from the Agencia Nacional de Promoción Científica y Tecnológica, Argentina (PICT 14087) and the Universidad de Buenos Aires (ME 075). DPC is a Research Career awarded from the Argentine Research Council (CONICET).

\section{References}

1. Cardinali DP, Bortman GP, Liotta G, Perez LS, Albornoz LE, Cutrera RA, Batista J, Ortega GP (2002) A multifactorial approach employing melatonin to accelerate resynchronization of sleep-wake cycle after a 12 time-zone westerly transmeridian flight in elite soccer athletes. J Pineal Res 32:41-46. doi:10.1034/ j.1600-079x.2002.10820.x

2. Cardinali DP, Gvozdenovich E, Kaplan MR, Fainstein I, Shifis HA, Perez LS, Albornoz L, Negri A (2002) A double blindplacebo controlled study on melatonin efficacy to reduce anxiolytic benzodiazepine use in the elderly. Neuroendocrinol Lett 23:55-60

3. Chaudhuri KR, Pal S, DiMarco A, Whately-Smith C, Bridgman K, Mathew R, Pezzela FR, Forbes A, Hogl B, Trenkwalder C (2002)
The Parkinson's disease sleep scale: a new instrument for assessing sleep and nocturnal disability in Parkinson's disease. J Neurol Neurosurg Psychiatry 73:629-635. doi:10.1136/jnnp.73.6.629

4. Chesson A Jr, Hartse K, Anderson WM, Davila D, Johnson S, Littner M, Wise M, Rafecas J (2000) Practice parameters for the evaluation of chronic insomnia. An American Academy of Sleep Medicine report. Standards of Practice Committee of the American Academy of Sleep Medicine. Sleep 23:237-241

5. Comella CL, Morrissey M, Janko K (2005) Nocturnal activity with nighttime pergolide in Parkinson disease: a controlled study using actigraphy. Neurology 64:1450-1451

6. Dhawan V, Dhoat S, Williams AJ, DiMarco A, Pal S, Forbes A, Tobias A, Martinez-Martin P, Chaudhuri KR (2006) The range and nature of sleep dysfunction in untreated Parkinson's disease (PD). A comparative controlled clinical study using the Parkinson's disease sleep scale and selective polysomnography. J Neurol Sci 248:158-162. doi:10.1016/j.jns.2006.05.004

7. Dhawan V, Healy DG, Pal S, Chaudhuri KR (2006) Sleep-related problems of Parkinson's disease. Age Ageing 35:220-228. doi: 10.1093/ageing/afj087

8. Dowling GA, Mastick J, Colling E, Carter JH, Singer CM, Aminoff MJ (2005) Melatonin for sleep disturbances in Parkinson's disease. Sleep Med 6:459-466. doi:10.1016/j.sleep.2005. 04.004

9. Fahn S, Elton RL, Members of the UPDRS committee (1987) Unified Parkinson's disease rating scale. In: Mardsen CD, Golstein M, Calne DB (eds) Recent developments in Parkinson's disease. MacMillan, New York, pp 153-163

10. Folstein MF, Folstein SE, McHugh PR (1975) Mini-mental state. A practical method for grading the cognitive state of patients for the clinician. J Psychiatr Res 12:189-198. doi:10.1016/00223956(75)90026-6

11. Garcia-Borreguero D, Larrosa O, Bravo M (2003) Parkinson's disease and sleep. Sleep Med Rev 7:115-129. doi:10.1053/ smrv.2002.0229

12. Grandas F, Iranzo A (2004) Nocturnal problems occurring in Parkinson's disease. Neurology 63:S8-S11

13. Happe S, Klosch G, Lorenzo J, Kunz D, Penzel T, Roschke J, Himanen SL, Gruber G, Zeitlhofer J (2005) Perception of sleep: subjective versus objective sleep parameters in patients with Parkinson's disease in comparison with healthy elderly controls. Sleep perception in Parkinson's disease and controls. J Neurol 252:936-943. doi:10.1007/s00415-005-0785-0 
14. Happe S, Ludemann P, Berger K (2002) The association between disease severity and sleep-related problems in patients with Parkinson's disease. Neuropsychobiology 46:90-96. doi:10.1159/ 000065418

15. Hoehn MM, Yahr MD (1967) Parkinsonism: onset, progression and mortality. Neurology 17:427-442

16. Hughes AJ, Daniel SE, Kilford L, Lees AJ (1992) Accuracy of clinical diagnosis of idiopathic Parkinson's disease: a clinicopathological study of 100 cases. J Neurol Neurosurg Psychiatry 55:181-184. doi:10.1136/jnnp.55.3.181

17. Martinez-Martin P, Salvador C, Menendez-Guisasola L, Gonzalez S, Tobias A, Almazan J, Chaudhuri KR (2004) Parkinson's disease sleep scale: validation study of a Spanish version. Mov Disord 19:1226-1232. doi:10.1002/mds.20144

18. McPartland RJ, Kupfer DJ, Foster FG, Reisler KL, Matthews G (1975) Objective measurement of human motor activity: a preliminary normative study. Biotelemetry 2:317-323

19. Means MK, Edinger JD, Glenn DM, Fins AI (2003) Accuracy of sleep perceptions among insomnia sufferers and normal sleepers. Sleep Med 4:285-296. doi:10.1016/S1389-9457(03)00057-1

20. Montgomery SA, Asberg M (1979) A new depression scale designed to be sensitive to change. Br J Psychiatry 134:382-389. doi:10.1192/bjp.134.4.382
21. Morgenthaler TI, Lee-Chiong T, Alessi C, Friedman L, Aurora RN, Boehlecke B, Brown T, Chesson AL Jr, Kapur V, Maganti R, Owens J, Pancer J, Swick TJ, Zak R (2007) Practice parameters for the clinical evaluation and treatment of circadian rhythm sleep disorders. An American Academy of Sleep Medicine report. Sleep 30:1445-1459

22. Razmy A, Lang AE, Shapiro CM (2004) Predictors of impaired daytime sleep and wakefulness in patients with Parkinson disease treated with older (ergot) vs newer (nonergot) dopamine agonists. Arch Neurol 61:97-102. doi:10.1001/archneur.61.1.97

23. Sateia MJ, Doghramji K, Hauri PJ, Morin CM (2000) Evaluation of chronic insomnia. An American Academy of Sleep Medicine review. Sleep 23:243-308

24. Trenkwalder C (1998) Sleep dysfunction in Parkinson's disease. Clin Neurosci 5:107-114

25. Tse W, Liu Y, Barthlen GM, Halbig TD, Tolgyesi SV, Gracies JM, Olanow CW, Koller WC (2005) Clinical usefulness of the Parkinson's disease sleep scale. Parkinsonism Relat Disord 11:317-321. doi:10.1016/j.parkreldis.2005.02.006 